\title{
Platelet-Activating Factor Receptor Is Essential for the Development of Experimental Cerebral Malaria
}

\author{
Norinne Lacerda-Queiroz, ${ }^{, \dagger}$ David H. Rodrigues, ${ }^{\dagger}$ \\ Márcia C. Vilela, ${ }^{\dagger}$ Milene A. Rachid, ${ }^{\dagger}$ \\ Frederico M. Soriani, ${ }^{\dagger}$ Lirlândia P. Sousa, ${ }^{\dagger \ddagger}$ \\ Roberta D.L. Campos, ${ }^{\dagger}$ Valerie F. J. Quesniaux, ${ }^{\S}$ \\ Mauro M. Teixeira, ${ }^{\dagger}$ and Antonio L. Teixeira ${ }^{\dagger \uparrow}$ \\ From the Department of Cell Biology* and the Laboratory of \\ Immunopharmacology/Department of Biochemistry and \\ Immunology, ${ }^{\dagger}$ Institute of Biological Sciences, and the \\ Department of Clinical Medicine, ${ }^{\text {I }}$ Faculty of Medicine, Federal \\ University of Minas Gerais, Minas Gerais, Brazil; the Department \\ of Clinical Analysis and Toxicology, ${ }^{\ddagger}$ Faculty of Pharmacy, Federal \\ University of Minas Gerais, Belo Horizonte, Brazil; and the \\ Molecular Immunology and Embryology Unit, ${ }^{\S}$ UMR6218, CNRS \\ and University of Orleans, Orleans, France
}

Cerebral malaria is a severe form of the disease that may result, in part, from an overt inflammatory response during infection by Plasmodium falciparum. The understanding of the pathogenesis of cerebral malaria may aid in the development of better therapeutic strategies for patients. The immune response in cerebral malaria involves elevation of circulating levels of cytokines and chemokines associated with leukocyte accumulation and breakdown of the bloodbrain barrier in the central nervous system. Plateletactivating factor (PAF) is a mediator of inflammation shown to orchestrate inflammatory processes, including recruitment of leukocytes and increase of vascular permeability. Using mice lacking the PAF receptor $\left(\mathrm{PAFR}^{-/-}\right)$, we investigated the relevance of this molecule for the outcome and the neuroinflammatory process triggered by $P$. berghei ANKA, an experimental model of cerebral malaria. In PAFR ${ }^{-/-}$mice, lethality was markedly delayed and brain inflammation was significantly reduced, as demonstrated by histology, accumulation, and activation of $\mathrm{CD8}^{+} \mathrm{T}$ cells, changes in vascular permeability and activation of caspase-3 on endothelial cells and leukocytes. Similarly, treatment with the PAFR antagonist UK-74,505 delayed lethality. Taken together, the results suggest that PAFR signaling is crucial for the development of experimental cerebral malaria. Mechanistically, PAFR activation is crucial for the cascade of events leading to changes in vascular permeability, accumulation, and activation of $\mathrm{CD8}^{+} \mathrm{T}$ cells and apoptosis of leukocytes and endothelial cells. (Am J Pathol 2012, 180: 246-255; DOI: 10.1016/j.ajpath.2011.09.038)

Malaria infection may present different clinical forms, from asymptomatic to a complicated form, called severe malaria. Severe malaria is a syndrome characterized by variable combination of severe anemia, respiratory distress syndrome, acidosis, and cerebral malaria (CM) as a consequence of Plasmodium falciparum infection. ${ }^{1}$

Although the exact pathogenesis of CM remains unclear, several mechanisms have been raised to explain it, including microvascular obstruction, and inflammatory and adaptive immunoresponses. ${ }^{2}$ Experimental cerebral malaria (ECM) does not reproduce human disease exactly, but it does exhibit some histopathological similarities, including changes in cerebral microvasculature, breakdown of the blood-brain barrier (BBB), petechial hemorrhages, congestion, and edema in brain. ${ }^{3}$ ECM is considered a useful model for understanding the immunopathogenesis of human $\mathrm{CM}$. In ECM induced by $P$. berghei ANKA (PbA) infection, $\mathrm{CD}^{+} \mathrm{T}$ cell accumulation and activation are crucial steps for the development of ECM. ${ }^{4-7}$ Other studies have found that concomitant brain accumulation of $\mathrm{CD}^{+} \mathrm{T}$ cells and recruitment of parasitized red blood cells ( $\mathrm{pRBC}$ ) also contribute for the development of $\mathrm{ECM}^{8}{ }^{8}$ Additionally, BBB is compromised after infection by $\mathrm{PbA}$ via induction of endothelial cells apoptosis by $\mathrm{CD}^{+} \mathrm{T}$ cells in a perforindependent process. ${ }^{9-11}$

Platelet-activating factor (PAF) is a phospholipid mediator of inflammation known to mediate recruitment and activation of leukocytes, increase of vascular permeability, and release of cytokines and chemokines. ${ }^{12}$ PAF acts

\footnotetext{
Supported with funds from Conselho Nacional de Desenvolvimento Científico e Tecnológico (CNPq), Fundação de Amparo à Pesquisa do Estado de Minas Gerais (Fapemig), and INCT em Dengue.

Accepted for publication September 16, 2011.

Address reprint requests to Norinne Lacerda-Queiroz, Ph.D., or Antonio Lucio Teixeira, Ph.D., Laboratory of Immunopharmacology, Sala 04202 , Instituto de Ciências Biológicas, Av. Antônio Carlos, 6627, Pampulha, Belo Horizonte, MG, Brazil. E-mail: norinneq@yahoo.com.br or altexr@gmail.com.
} 
via a single G-protein-coupled receptor (PAFR), which may be expressed on cellular and nuclear membranes of leukocytes, endothelial cells, and platelets. ${ }^{13}$ We hypothesized that PAF/PAFR pathway may play an essential role in the development of ECM by controlling relevant pathways needed for development of disease, including leukocyte infiltration, changes in vascular permeability, and apoptosis of relevant cell types. PAFR-deficient mice were used to address the involvement of PAFR for the outcome of infection caused by $\mathrm{PbA}$ and the associated inflammatory process. The relevance of this pathway for infection outcome was further confirmed using a long-lasting, selective PAFR antagonist, UK74,505. ${ }^{14}$ Our results show that the absence or pharmacological blockade of PAFR confers significant protection against ECM caused by $\mathrm{PbA}$.

\section{Materials and Methods}

\section{Animals}

Wild-type (WT) C57BL/6 (6 to 8 weeks old) mice were obtained from the Animal Care Facilities of Universidade Federal de Minas Gerais, Minas Gerais, Brazil. PAFR ${ }^{-1-}$ mice with a C57BL/6 genetic background were the gift of Dr. Takao Shimizu (University of Tokyo, Japan) and were bred and maintained under specific-pathogen-free conditions at the Instituto de Ciências Biológicas, Universidade Federal de Minas Gerais. The animal ethics committee of the Universidade Federal de Minas Gerais approved all experimental procedures used (protocol no. 193/06).

\section{Experimental Infection}

Mice were infected with PbA by i.p. injection of $10^{6} \mathrm{pRBC}$ suspended in $0.2 \mathrm{~mL}$ PBS. ${ }^{15}$ The percentage of parasitemia in infected mice was monitored on Giemsa-stained blood films from day 3 onward and estimated at 1000 RBCs under immersion oil. Mice were observed daily for body weight measurement, survival, and clinical neurological signs of ECM culminating in ataxia, paralysis, and coma.

\section{Histopathology}

Mice were euthanized and brains were immediately removed and fixed in $10 \%$ buffered formalin for histological analysis. The sections $(4 \mu \mathrm{m})$ were stained with $\mathrm{H} \& \mathrm{E}$, then evaluated by a pathologist blinded to the experiment. Brain microvascular obstruction was evaluated by scoring the number of vessels containing sequestered blood cells on multiple fields corresponding to whole brain sections $(0 \%$ microvascular obstruction $=0 ; 1 \%$ to $19 \%$ microvascular obstruction $=1 ; 20 \%$ to $39 \%$ microvascular obstruction $=2 ; 40 \%$ to $59 \%$ microvascular obstruction $=$ 3; $60 \%$ to $79 \%$ microvascular obstruction $=4$; and $80 \%$ microvascular obstruction $=5$ ), as described in Fauconnier et al. ${ }^{16}$ The area of hemorrhage from cerebellum was measured in 10 sections obtained for each animal; there were five animals per group. Sections were captured with a digital camera (DEI-470; Optronics, Goleta, CA) connected to a microscope (IX70; Olympus, Center Valley, PA) with a magnification of $\times 200$. Hemorrhagic areas were measured in the software Image Pro-Plus version 6.0 (Media Cybernetics, Silver Spring, MD). Results were expressed as the mean cerebellar hemorrhagic area $\left(\mu \mathrm{m}^{2}\right)$ per field.

\section{Intravital Microscopy in Mouse Brain}

Intravital microscopy of mouse brain microvasculature was performed as previously described. ${ }^{17}$ Briefly, control and infected mice ( 3 and 6 days after inoculation) were anesthetized by an i.p. injection of a mixture of ketamine (150 mg/kg; Laboratório Cristália, São Paulo, Brazil) and xylazine (10 mg/kg, Rompun; Bayer, Montville, NJ), and the tail vein was cannulated for administration of rhodamine $6 G$. The craniotomy was performed with a highspeed drill (Beltec, São Paulo, Brazil), and the dura and arachnoid mater were removed to expose the underlying pial vasculature. Throughout the experiment, the mice were maintained at $37^{\circ} \mathrm{C}$ with a Thermo Plate (Tokai Hit; Nikon, Tokyo, Japan), and the exposed brain was continuously superfused with artificial cerebrospinal fluid buffer, an ionic composition (mmol/L): $\mathrm{NaCl} 132, \mathrm{KCl}$ 2.95, $\mathrm{CaCl}_{2}$ 1.71, $\mathrm{MgCl}_{2} 0.64, \mathrm{NaHCO}_{3}$ 24.6, dextrose 3.71, and urea 6.7, $\mathrm{pH} \mathrm{7.4,} \mathrm{at} 37^{\circ} \mathrm{C}$.

To observe leukocyte/endothelium interactions, leukocytes were fluorescently labeled by i.v. administration of rhodamine 6G (0.3 mg/kg; Sigma-Aldrich, St. Louis, MO) and observed using a microscope (Eclipse 501; Nikon; $\times 10$ objective lens, corresponding to $100 \mu \mathrm{m}$ of area) outfitted with a fluorescent light source (epi-illumination at 510 to $560 \mathrm{~nm}$, using a 590-nm emission filter). A camera (DS-Qi1MC; Nikon) mounted on the microscope projected the image onto a monitor (FLATRON-W1952TQ; LG Electronics, Seoul, South Korea). The number of rolling and adherent leukocytes was determined offline during video playback analysis. Leukocytes were considered adherent to the venular endothelium if they remained stationary for a minimum of 30 seconds and expressed as number of cells per $100 \mu \mathrm{m}$. Rolling leukocytes were defined as white cells moving at a velocity lower than that of erythrocytes within a given vessel.

\section{Lysate Preparation and Western Blot Analysis}

Western blot analysis for cleaved caspase-3 was performed as previously described. ${ }^{18}$ Briefly, whole cell extracts were obtained from homogenized brains by using a lyses buffer [1\% (v/v) Triton X-100, $100 \mathrm{mmol} / \mathrm{L}$ Tris/HCl, $\mathrm{pH}$ 8.0, 10\% (v/v) glycerol, 5 mmol/L EDTA, $200 \mathrm{mmol} / \mathrm{L}$ $\mathrm{NaCl}, 1 \mathrm{mmol} / \mathrm{L}$ dithiothreitol, $1 \mathrm{mmol} / \mathrm{L}$ phenylmethyl sulfonyl fluoride, $25 \mathrm{mmol} / \mathrm{L} \mathrm{NaF}, 2.5 \mu \mathrm{g} / \mathrm{mL}$ leupeptin, 5 $\mu \mathrm{g} / \mathrm{mL}$ aprotinin, and $1 \mathrm{mmol} / \mathrm{L}$ sodium orthovanadate]. Lysates were centrifuged at $13,000 \times g$ for 10 minutes at $4^{\circ} \mathrm{C}$ and quantified using the Bradford assay reagent from Bio-Rad (Hercules, CA). Protein extracts $(25 \mu \mathrm{g})$ were separated by electrophoresis on a denaturing $15 \%$ polyacrylamide-SDS gel and transferred onto nitrocellulose membranes. Membranes were blocked overnight at $4^{\circ} \mathrm{C}$ with PBS containing $5 \%(\mathrm{w} / \mathrm{v})$ nonfat dry milk and $0.1 \%$ Tween-20 and washed three times with PBS containing $0.1 \%$ Tween-20. The membranes were then incu- 
bated with rabbit anti-cleaved caspase-3 (Cell Signaling Technology, Beverly MA) or mouse anti- $\beta$-actin (SigmaAldrich) using a dilution of 1:1000 in PBS containing 5\% $(\mathrm{w} / \mathrm{v})$ bovine serum albumin and $0.1 \%$ Tween-20. After washing, the membrane was incubated with appropriate horseradish peroxidase conjugated secondary antibody (1:3000). Immunoreactive bands were visualized by using an enhanced chemiluminescence detection system, as described by the manufacturer (GE Healthcare, Piscataway, NJ). The levels of cleaved caspase-3 were quantified by using a densitometric analysis software (ImageJ software version 1.45; $\mathrm{NIH}$, Bethesda, MD), and the values were normalized to the values of $\beta$-actin in the same sample. Changes in protein levels were estimated, and the results were expressed as a cleaved caspase- $3 / \beta$-actin ratio, measured in arbitrary units.

\section{Immunohistochemistry}

Endothelial cells immunoreactive for cleaved caspase-3 were analyzed in situ after staining with relevant antibodies. Brain sections $(4 \mu \mathrm{m})$ from formalin-fixed, paraffinembedded tissue were submitted to antigen unmasking with sodium citrate buffer $(\mathrm{pH} 6)$ for 20 minutes, washed, and blocked for endogenous peroxidase activity (3\% $\mathrm{H}_{2} \mathrm{O}_{2}$ in $\mathrm{PBS} /$ bovine serum albumin $1 \%$ ) for 30 minutes. Slides were then washed and blocked with PBS containing 5\% (w/v) nonfat dry milk and $0.1 \%$ Tween-20. All incubations were performed in a wet chamber. Brain sections were then incubated with rabbit monoclonal antibody against activated caspase-3 (Cell Signaling Technology), which was diluted 1:500 and permitted to bind overnight at $4^{\circ} \mathrm{C}$. Biotinylated link and streptavidinhorseradish peroxidase (Dako, Glostrup, Denmark) were applied, and after washing, sections were incubated with peroxidase substrate (diaminobenzidine; Dako). Sections without primary antibodies were equally processed to control for unspecific binding. Finally, sections were counterstained with hematoxylin, washed, mounted, and examined under a light microscope and scored by a pathologist blinded to the experiment. Cell immunoreactivity for cleaved caspase- 3 were scored 0 to 4 using the following point scale: $0=$ no signal; $1=$ minimal; $2=$ mild; $3=$ moderate; and $4=$ intense.

\section{Assessment of BBB Integrity}

The integrity of the BBB was investigated using Evans blue (EB) dye as previously reported. ${ }^{19}$ Mice were injected i.v. with $0.2 \mathrm{~mL}$ of $1 \%$ EB solution (Sigma-Aldrich) on day 6 . One hour later, mice were sacrificed and perfused intracardially with $5 \mathrm{~mL}$ of PBS. Brain samples were removed and weighted, and EB extravasation was evaluated by formamide incubation $(1 \mathrm{~mL})$ for 24 hours. The amount of EB in tissue extracts was measured by absorbance at $610 \mathrm{~nm}$ as an index of increased capillary permeability. Results are shown as the amount of EB (pg) present in $100 \mathrm{mg}$ of brain tissue.

\section{Gene Expression Analysis by Real-Time Quantitative PCR}

Brains were removed for analysis of transcript levels of $\mathrm{IL}-1 \beta, \mathrm{IL}-10$, and $\mathrm{CXCL} 10$, as well as of molecules involved in adhesion process, such as intercellular adhesion molecule-1 (ICAM-1) and vascular cell adhesion molecule-1 (VCAM-1). The primers used are listed in Table 1. Total RNA was obtained using Trizol (Invitrogen, Carlsbad, CA) according to the procedure supplied by the manufacturer. Total RNA was reverse transcribed with SuperScript III (Invitrogen) as described by the manufacturer. Real-time quantitative PCR was performed on an $\mathrm{ABI}$ PRISM Step-One sequence-detection system (Applied Biosystems, Carlsbad, CA) using SYBR Green PCR Master Mix (Applied Biosystems). The relative expression level of genes was determined by the $2(-\Delta \Delta \mathrm{Ct})$ method, and data were normalized by $18 \mathrm{~S}$ ribosome subunit expression levels. All reactions were replicated.

\section{Study of Cytokines in the Central Nervous System}

Brain tissues were obtained from control and infected mice (on day 6 after inoculation) and homogenized in extraction solution containing aprotinin. The levels of CCL2, CCL3, CCL5, and CXCL1 were determined by enzyme-linked immunosorbent assay (ELISA). The samples, at a $1: 3$ dilution in PBS/bovine serum albumin $0.1 \%$, were assayed in an ELISA set up using commercially available antibodies and the concentrations according to

Table 1. Oligonucleotide Primers for Real-Time Quantitative PCR

\begin{tabular}{|c|c|c|}
\hline Gene & Direction & Primer sequence \\
\hline \multirow[t]{2}{*}{$m / L-10$} & Forward & 5'-GCTCTTACTGACTGGCATGAG-3' \\
\hline & Reverse & 5'-CGCAGCTCTAGGAGCATGTG-3' \\
\hline \multirow[t]{2}{*}{$m / L-1 \beta$} & Forward & $5^{\prime}$-CTACAGGCTCCGAGATGAACAAC-3' \\
\hline & Reverse & 5'-TCCATTGAGGTGGAGAGCTTTC-3' \\
\hline \multirow[t]{2}{*}{$m C X C L 10$} & Forward & $5^{\prime}-$ CTCGCAAGGACGGTCCGCTG- $3^{\prime}$ \\
\hline & Reverse & $5^{\prime}$-CGTGGCAATGATCTCAACACGTGG-3' \\
\hline \multirow[t]{2}{*}{ mVCAM-1 } & Forward & $5^{\prime}$-CCCCAAGGATCCAGAGATTCA-3' \\
\hline & Reverse & 5'-ACTTGACCGTGACCGGCTT-3' \\
\hline \multirow[t]{2}{*}{$m / C A M-1$} & Forward & $5^{\prime}$-ATCTCAGGCCGCAAGGG-3' \\
\hline & Reverse & $5^{\prime}-$ CGAAAGTCCGGAGGCTCC $-3^{\prime}$ \\
\hline \multirow[t]{2}{*}{ m18S } & Forward & $5^{\prime}$-CGTTCCACCAACTAAGAACG-3' \\
\hline & Reverse & 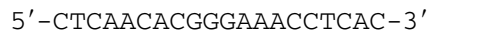 \\
\hline
\end{tabular}


the procedures supplied by the manufacturer (R\&D Systems, Minneapolis, MN; BD Pharmingen, San Diego, CA).

\section{Isolation of Leukocytes in the Central Nervous System}

Mice were euthanized on day 7 after inoculation, a time point when all WT mice showed neurological symptoms of $\mathrm{ECM}$. They were perfused intracardially with PBS to remove both circulating and nonadherent RBCs and leukocytes. Brains were removed and adherent leukocytes isolated using previously described protocols. ${ }^{16,20}$ Each sample comprises a pool of two to three mice brains. Briefly, brains were collected and homogenized gently with a sterile glass tissue grinder in RPMI 1640 medium containing 5\% fetal calf serum. Homogenates were passed through a nylon cell strainer (70 $\mu \mathrm{m}$; Becton Dickinson, San Jose, CA) and then centrifuged at $400 \times g$ for 10 minutes. The pellet was resuspended in $35 \%$ Percoll gradient (Sigma-Aldrich), and this was deposited on a $70 \%$ Percoll gradient. After centrifugation $(1100 \times g)$, myelin was aspirated off the top of the $35 \%$ Percoll layer and leukocytes were collected at the boundary layer, between the $70 \%$ and $35 \%$ gradient. Afterward, leukocytes were resuspended in fluorescence-activated cell sorting buffer (PBS containing 1\% fetal calf serum and $0.01 \% \mathrm{NaN}_{3}$ ) and counted.

\section{Immunolabeling and Fluorescence-Activated Cell Sorting Analysis}

Brain-sequestered cells were stained for extracellular molecular expression patterns using monoclonal antibodies against mouse CD3 conjugated to phycoerythrin (BD Pharmingen; clone 17A2), CD8 $\alpha$ conjugated to fluorescein isothiocyanate (BD Pharmingen; clone 53-6.7), CD62L conjugated to phycoerythrin-Cy5 (BioLegend; clone MEL-14), and isotype controls (all from BD Pharmingen). For each sample, 20,000 cells from lymphocyte population were scored. The frequency of positive cells was analyzed using a gate that included lymphocytes. Limits for the quadrant markers were always set on the basis of negative populations and isotype controls. Data were acquired on a FACScan (Becton Dickinson) and analyzed by FlowJo 7.5.3 software (TreeStar Inc., Ashland, OR). Results are presented as absolute number of cells per brain or mean fluorescence intensity as indicated.

\section{Treatment with UK-74,505}

PAFR antagonist UK-74,505 (10 mg/kg), diluted in $0.1 \%$ $(\mathrm{v} / \mathrm{v}) \mathrm{HCl}$ in PBS, was provided orally, by gavage, once a day, from day 3 after infection in C57BL/6 animals. ${ }^{21}$ Control group (vehicle) received the same volume of the solution used to dilute UK-74,505. Parasitemia, body weight variations, and survival were analyzed.

\section{Statistical Analysis}

Data are shown as mean \pm SEM. Differences between groups were analyzed by analysis of variance with Newman-Keuls posttest for multiple comparisons or by a nonparametric Mann-Whitney test for analysis of small groups. Survival rates were compared by a log-rank test. Statistical significance was set at $P<0.05$.

\section{Results}

\section{Deficiency in PAFR Prevents the Development of ECM}

Inoculation of WT C57BL/6 mice with PbA induced parasitemia that was first detectable on day 3 and increased significantly thereafter (Figure 1A). Parasitemia was associated with significant weight loss (Figure 1B), and most animals were dead at day 7 after inoculation (Figure 1C). Parasitemia and weight loss in $\mathrm{PAFR}^{-1-}$ mice were similar to those found in WT mice until day 7. However, $\mathrm{PAFR}^{-1-}$ mice recovered their weight, and most animals survived $(60 \%)$ past day 7 after inoculation. Thereafter, parasitemia increased significantly in $\mathrm{PAFR}^{-1-}$ mice, and approximately $60 \%$ of RBCs were infected at day 20 , after which time most animals died of infection. Increase in parasitemia was associated with a second wave of weight loss in PAFR ${ }^{-1-}$ mice. Taken together, these studies show that absence of PAFR protected mice against ECM after $\mathrm{PbA}$ infection.

\section{Infected PAFR ${ }^{-1-}$ Mice Present Mild Histopathological Changes in Brain}

A series of experiments were then undertaken to try to understand why $\mathrm{PAFR}^{-1-}$ mice survive for longer than WT mice. Control and infected mice sacrificed at day 3
A

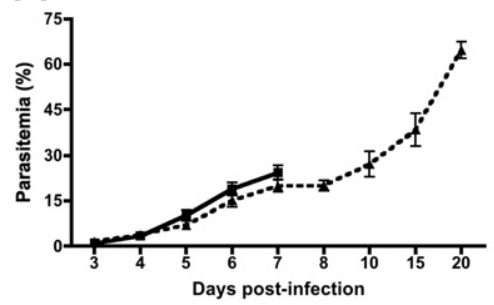

B

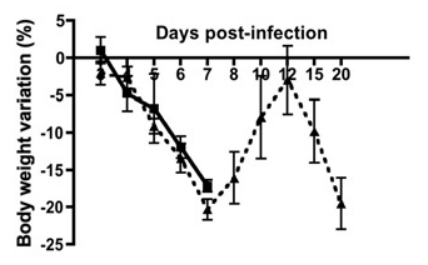

C

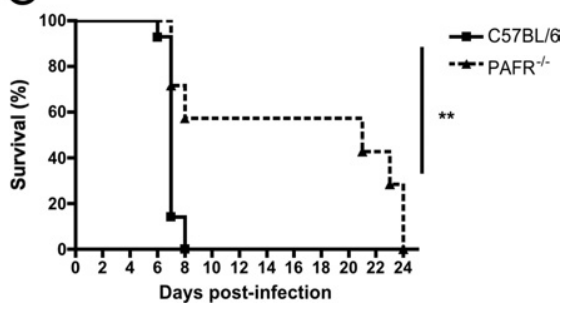

Figure 1. Increased resistance in $\mathrm{PAFR}^{-1-}$ mice infected with PbA. Time courses of parasitemia $(\mathbf{A})$ and body weight variation $(\%)(\mathbf{B})$ in infected WT $(n=8)$ and infected PAFR ${ }^{-1}(n=7)$ mice infected with $10^{6}$ pRBC. Significant difference was not observed between the groups until day 7 after inoculation. C:Percentage of survival in PbA-infected mice. WT (solid lines, $n=14$ ) and PAFR ${ }^{-1-}$ mice (dashed lines, $n=7$ ). The survival curve of PAFR ${ }^{-1}$ was significantly different (21 days after inoculation) of WT ( 7 days after inoculation). ${ }^{* * *} P<0.01$. Each point of parasitemia and weight loss is expressed as mean \pm SEM. Results are representative of two independent experiments. 


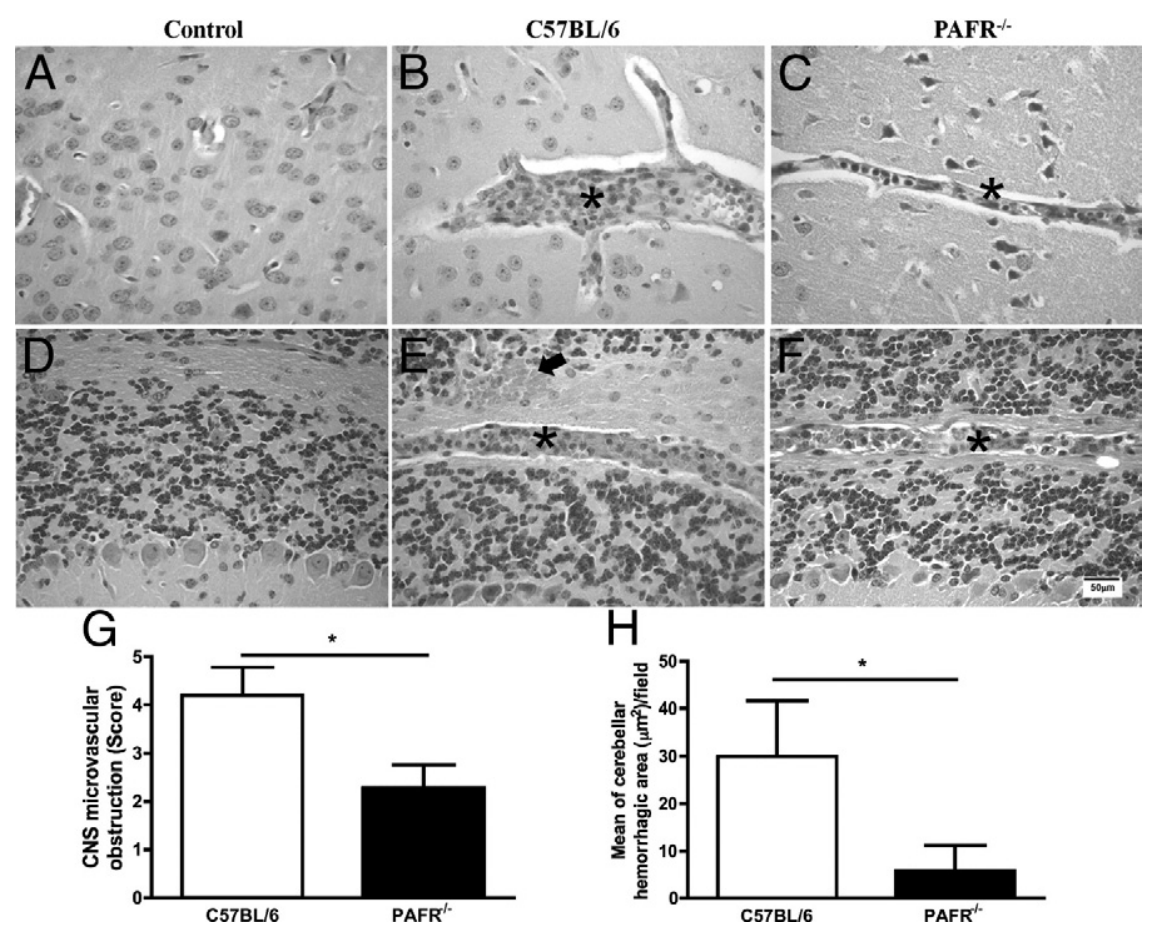

Figure 2. Infected $\mathrm{PAFR}^{-/-}$mice present mild histopathological changes in brain. Representative photomicrographs (original magnification, $\times 400$ ) of H\&E-stained brain sections from uninfected control mice (A and $\mathbf{D})$, or PbA-infected $\mathrm{C} 57 \mathrm{BL} / 6(\mathbf{B}$ and $\mathbf{E})$ and PAFR ${ }^{-1}(\mathbf{C}$ and $\mathbf{F})$ mice on day 6 after inoculation. Normal histological of cerebrum (A) and cerebellum (D). PbA-infected C57BL/6 showing intravascular leukocyte accumulation (asterisk) in cerebrum (B) and cerebellum (E). Note also focal cerebellar hemorrhage (arrow). In contrast, $\mathrm{PAFR}^{-/-}$mouse exhibit less intense vascular plugging (asterisk) in the cerebrum $(\mathbf{C})$ and less cerebellar hemorrhage (F) compared to $\mathrm{C} 57 \mathrm{BL} / 6$-infected mice. The severity of microvascular obstruction and cerebellar hemorrhagic areas $\left(\mu \mathrm{m}^{2} /\right.$ field $) \mathrm{dem}-$ onstrated a significant reduction in brain disease in $\mathrm{PAFR}^{-1-}$ mice $(\mathbf{G}$ and $\mathbf{H}) .{ }^{*} P<0.05$ when compared to $\mathrm{C} 57 \mathrm{BL} / 6$-infected infected mice ( $n=5$ minimum).

after inoculation had no evidence of morphological changes in the brain (data not shown). On day 6 after inoculation, there was intense intravascular leukocyte accumulation and vascular plugging in various brain regions of WT infected mice (Figure 2). Semiquantification experiments showed that microvascular obstruction was in general less severe in PAFR ${ }^{-1-}$ than WT mice (Figure $2 \mathrm{G})$. There were also hemorrhagic areas, especially in the cerebellum of WT infected mice (Figure 3, E and H).
Cerebellar hemorrhage was virtually absent in infected PAFR $^{-1-}$ mice (Figure 3, F and $\mathrm{H}$ ).

\section{Rolling and Adhesion of Leukocytes in Pial Vessels Is Independent of PAFR}

Because there was decreased inflammation in infected $\mathrm{PAFR}^{-1-}$ mice, we investigated whether this receptor
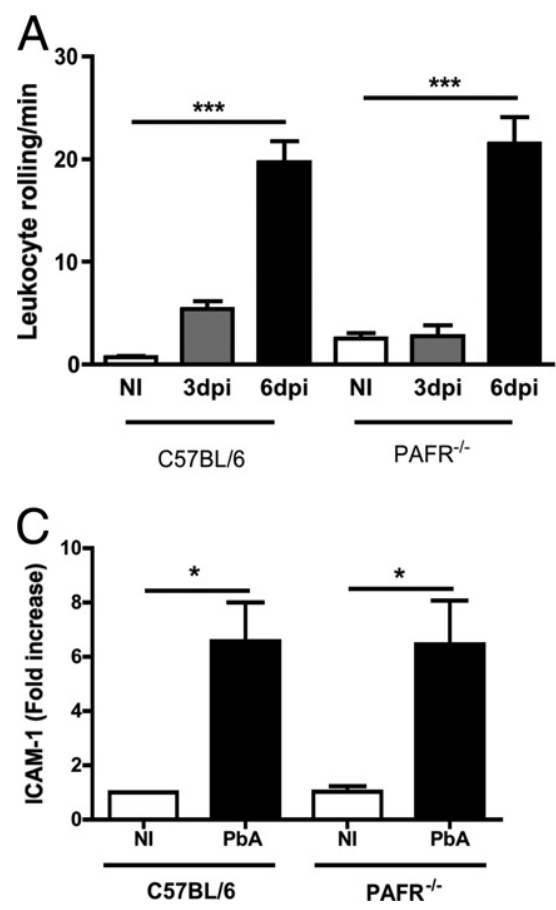
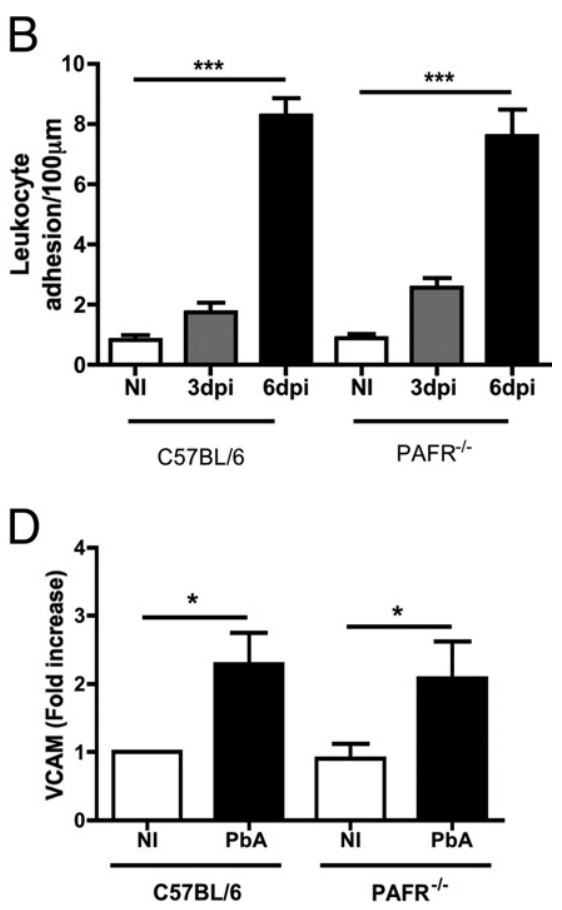

Figure 3. Rolling and adhesion of leukocytes in pial vessels. Leukocyte-endothelium interaction was performed by intravital microscopy to assess rolling (A) and adhesion (B) of leukocytes in brain microvasculature. The protocol included control and infected WT and PAFR ${ }^{-1}$ mice. Infected mice, on day 6 after inoculation, showed an increase in leukocyte-endothelium interaction when compared with their respective controls. Cell rolling and adhesion was similar between infected WT and infected $\mathrm{PAFR}^{-/}$ mice. Transcript levels of ICAM-1 (C) and VCAM-1 (D) were significantly increased in infected groups at day 6 after inoculation. Results are expressed as mean \pm SEM and are representative of two independent experiments $(n=5)$. Significant differences are indicated by ${ }^{*} P<$

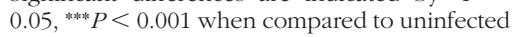
control counterparts. 
A

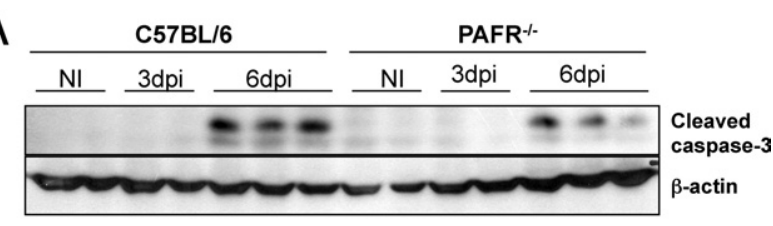

B

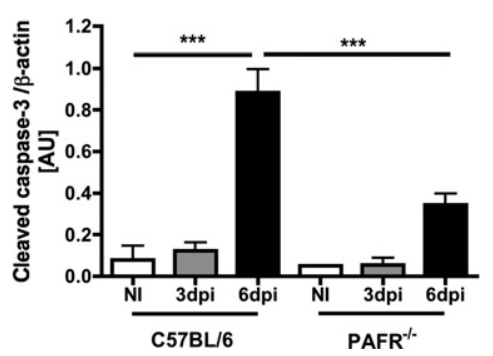

Figure 4. Reduced cleavage of caspase-3 in brain extracts of infected PAFR $^{-/-}$mice. Western blot analysis of brain levels of cleaved caspase- 3 in WT and $\mathrm{PAFR}^{-1-}$ mice after PbA infection (for control and 3 days after inoculation, $n=2$; for 6 days after inoculation, $n=3$ ). Samples were collected and processed for protein extraction. Brain extracts $(25 \mu \mathrm{g})$ were fractioned on $15 \%$ SDS-PAGE, transferred onto nitrocellulose membrane, and then probed with anti-cleaved caspase- 3 or anti- $\beta$-actin antibodies for loading control (A). Densitometric analysis of Western blot membranes by ImageJ software are presented as arbitrary units (B). Results are expressed as mean \pm SEM and are representative of two independent experiments. * $^{*} * P<$ 0.001 , when compared to uninfected control counterparts or when compared to WT infected mice.

played any significant role for the recruitment of cells into the brain of infected mice. Intravital microscopy in the pia mater vasculature was used to measure rolling and adhesion induced by $\mathrm{PbA}$ infection. Infected animals had an increase in the number of leukocytes rolling and adhering on endothelium at day 6 after inoculation when compared to uninfected control animals (Figure 3, A and B), an event that precedes death in these animals (Figure 1). Infected PAFR ${ }^{-1-}$ mice had similar increase in leukocyte rolling and adhesion as infected WT 6 days after inoculation. The cell adhesion molecules ICAM-1 and VCAM-1 are relevant for the sequestration of leukocytes to the brain of animals in the context of ECM. ${ }^{22}$ Transcript levels of ICAM-1 and VCAM-1 were significantly increased in both WT and PAFR ${ }^{-1-}$ infected mice at day 6 after inoculation (Figure 3, C and D).

\section{PAFR Deficiency Attenuates Caspase-3 Activation and Brain Vascular Permeability on PbA Infection}

Caspase-3-mediated apoptosis of endothelial cells occurs in ECM and may be relevant for the pathogenesis of disease. ${ }^{23}$ To determine whether PAFR regulates activation of caspase- 3 in the course of ECM, brain extracts from WT and PAFR ${ }^{-1-}$ mice were examined for the presence of cleaved subunits of caspase-3 (17/19 kDa) (Figure 4A). In infected WT mice, densitometry measures revealed a marked increase of caspase-3 17/19 $\mathrm{kDa}$ subunits at day 6 after inoculation. Caspase-3 activation was significantly lower in infected PAFR $^{-1-}$ mice (Figure 4B).

Consistent with the finding of activated caspase-3 by immunoblotting, cells immunoreactive for activated caspase-3 were observed in brain samples of infected mice on day 6 after inoculation. Caspase- $3^{+}$cells were frequently clustered around vessels with caspase $-3^{+}$endothelial cells and sequestered leukocytes (Figure 5B). In contrast, activated caspase-3 immunoreactivity was absent in brain tissue from noninfected animals (Figure $5 A$ ). Infected $\mathrm{PAFR}^{-1-}$ mice showed less number of caspase $-3^{+}$cells than infected WT mice (Figure 5, C and D). Because the administration of PAF has been associated with increased vascular permeability, ${ }^{24}$ the integrity of BBB was investigated next. At day 6 after inoculation, BBB integrity was determined by measuring EB extravasation into the cerebral parenchyma. There was clearly visible vascular leakage of $\mathrm{EB}$ in PbA-infected WT mice, whereas $\mathrm{PAFR}^{-1-}$ mice exhibited no discoloration of the brain parenchyma (Figure 6A). When the extravasation of EB was quantified, there was over $75 \%$ decrease in the amount of EB in the brain of infected

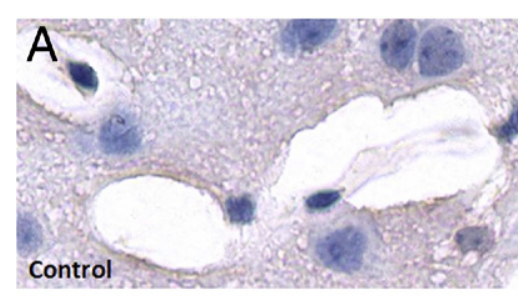

Figure 5. Reduced immunoreactive cells for cleaved caspase-3 in brain of infected $\mathrm{PAFR}^{-1-}$ mice. Representative photomicrographs (original magnification, $\times 400$ ) of immunohistologic staining for cleaved caspase- 3 are presented from brain slides of uninfected control mice $(\mathbf{A})$, or PbA-infected $(\mathbf{B})$ and PAFR ${ }^{-/-}(\mathbf{C})$ mice on day 6 after inoculation. Activated caspase-3 immunoreactivity was absent in tissue from control animals (A). PbA-infected mice showed immunoreactive sequestered leukocytes frequently clustered around vessels with immunoreactive endothelial cells (asterisk) (B). In contrast, $\mathrm{PAFR}^{-1-}$ mouse exhibited less intense immunoreactive cells (asterisk) (C) when compared to infected WT mice. Quantification of immunoreactive cells for activated caspase-3 demonstrated a significant reduction in $\mathrm{PAFR}^{-1-}$ mice $(\mathbf{D}) .{ }^{*} P<0.05$ when compared to infected WT mice ( $n=5$ to 7 ).
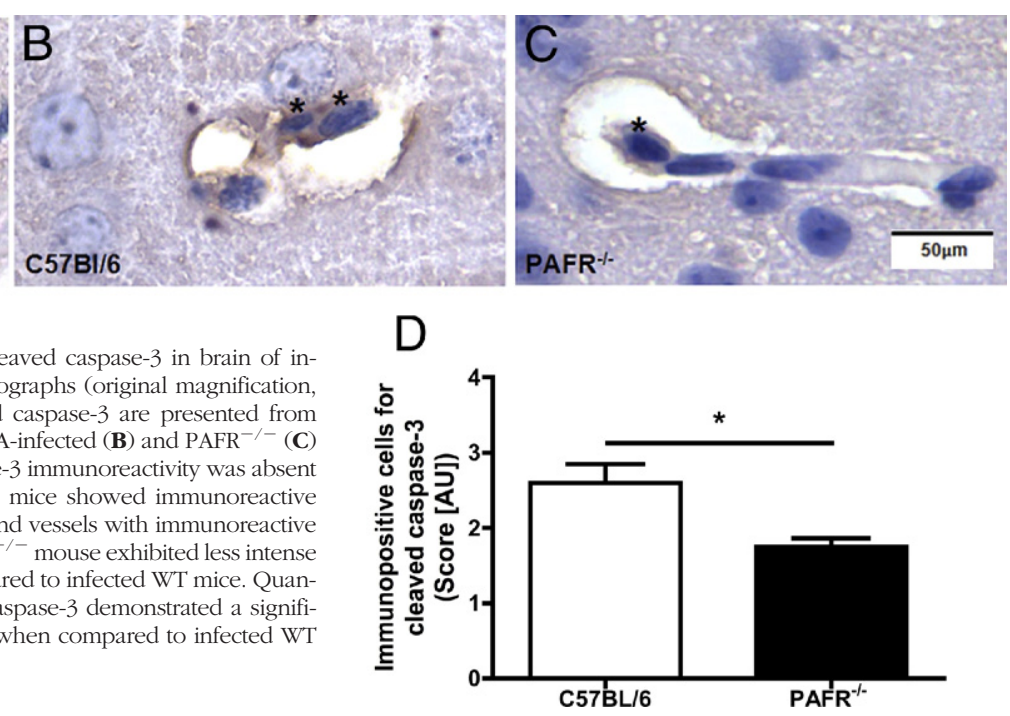
A

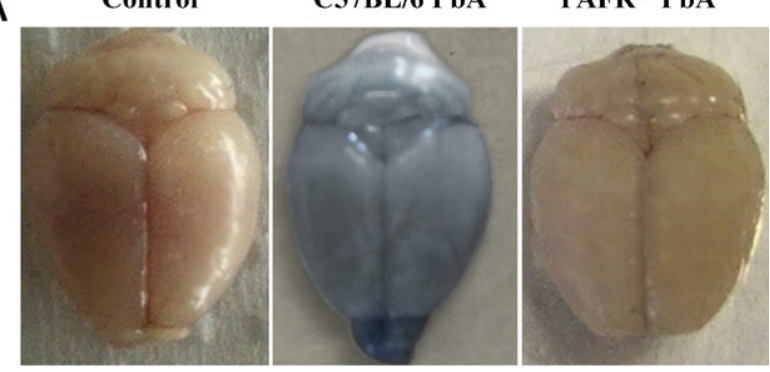

B

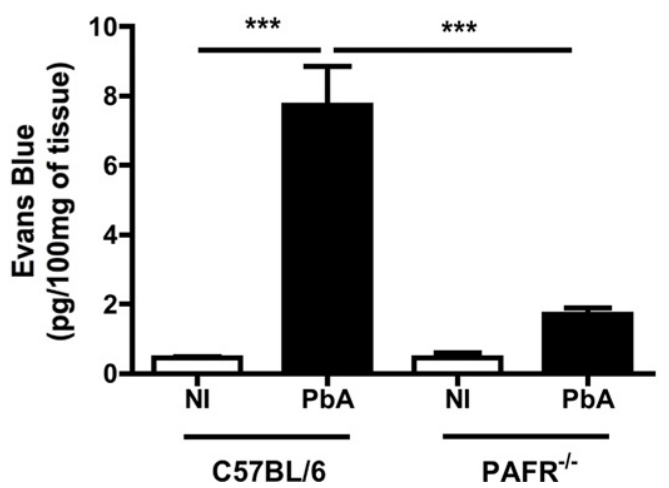

Figure 6. $\mathrm{PAFR}^{-/-}$mice do not develop ECM-associated brain vascular leakage. Evaluation of BBB breakdown by determination of Evans blue concentration in cerebral parenchyma. A: Qualitative assessment of brain vascular leak using Evans blue extravasation. Mice with severe CM infection on day 6 after inoculation exhibited blue discoloration of the brain, whereas control mice and infected PAFR ${ }^{-1-}$ mice demonstrated no discoloration. B: Quantitative assessment of brain vascular permeability using Evans blue extravasation in formamide was made by absorbance at $610 \mathrm{~nm}$ in brain extract. PbA-infected mice showed significant EB concentration in cerebral parenchyma, whereas infected $\mathrm{PAFR}^{-9-}$ mice exhibited no EB extravasation. Values are given as mean $\pm \operatorname{SEM}(n=5)$ from two different experiments Significant differences are indicated by ${ }^{\text {**** }} P<0.001$ when compared to control counterparts or when compared to infected WT mice.

mice (Figure 6B), indicating preserved BBB integrity in $\mathrm{PAFR}^{-1-}$ mice. Taken together, these data demonstrate cerebral vascular protection in the absence of PAFR in PbA-induced ECM.

\section{Analysis of Cytokine Expression and Chemokine Molecules in the Brain}

Regarding the role of CXCL10 and IL-10 in the pathogenesis of $\mathrm{ECM},{ }^{25,26}$ and once IL-1 $\beta$ can contribute to BBB damage, ${ }^{27}$ we evaluated transcript levels of these molecules by quantitative PCR. Levels of these cytokines/ chemokine could not be determined consistently by ELISA (data not shown). PbA infection induced significant expression of pro-IL-1 $\beta$ increased in the brain of WT mice. In PAFR ${ }^{-1-}$ mice, this increase was not significant (Figure 7A). Expression of IL-10 and CXCL10 was similar in both WT and PAFR ${ }^{-1-}$ mice (Figure $7, \mathrm{~B}$ and $\mathrm{C}$ ).

We evaluated the levels of the following chemokines by ELISA in brain extracts: CCL2, CCL3, CCL5, and CXCL1. Infection of WT mice with $\mathrm{PbA}$ was associated with an increase in levels of CCL2 and CCL5 (Figure 7, D and E). In contrast, there was no increase of CCL3 and CXCL1 after infection of WT mice (data not shown). In $\mathrm{PAFR}^{-1-}$ mice, there was an increase in levels of both CCL2 and CCL5, but the increase in CCL2 levels was slightly lower than that observed in WT infected mice. Therefore, pro-IL-1 $\beta$ message and CCL2 protein were significantly less expressed in the brain of PAFR ${ }^{-1-}$ than WT mice after PbA infection.

\section{Absence of PAFR Reduces Cerebral T-Cell Sequestration and Activation}

Some studies have shown that activated $\mathrm{CD}^{+} \mathrm{T}$ cells play a crucial role in the pathogenesis of ECM. ${ }^{4-7}$ Therefore, we measured the number and state of activation of $\mathrm{CD}^{+} \mathrm{T}$ cells in the brain of WT and PAFR ${ }^{-1-}$ mice at day 7 after inoculation, a time point when typical neurological symptoms of ECM are established. There was significant increase in number of $\mathrm{CD}^{+} \mathrm{T}$ cells in the brain of WT and $\mathrm{PAFR}^{-1-}$ mice after PbA infection (Figure 8A). However, the increase of $\mathrm{CD}^{+} \mathrm{T}$ cells observed in infected PAFR $^{-1-}$ mice was $39 \%$ lower than that observed in WT mice. Activation of $\mathrm{CD}^{+} \mathrm{T}$ cells was investigated by evaluating surface expression of CD62L. PbA infection
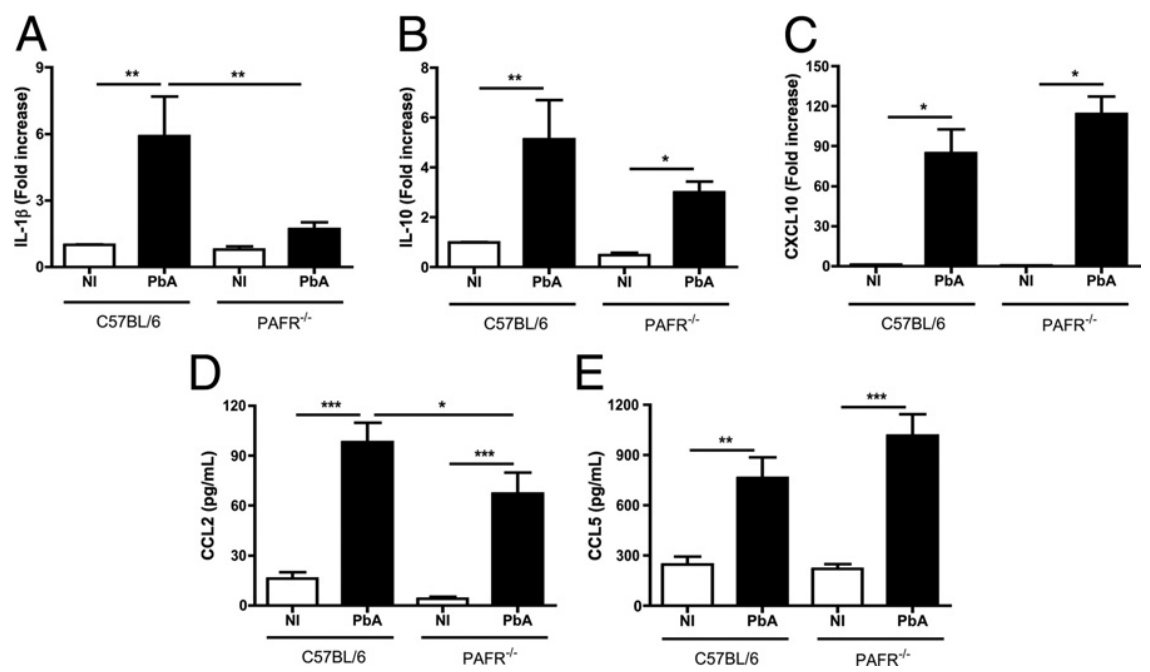

$\mathrm{E}$

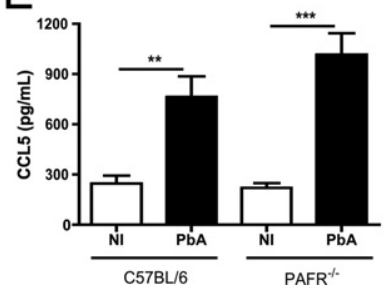

Figure 7. Analysis of chemokines and mRNA cytokine in the brain of PbA-infected mice. mRNA expression of IL- $1 \beta$, IL-10, and CXCL10 in the brain by quantitative PCR. Transcript levels of IL-1 $\beta$ (A) were significantly greater in the brains of infected WT mice, in contrast to unchanged levels in infected $\mathrm{PAFR}^{-/-}$mice. Expression of IL-10 (B) and CXCL10 (C) was higher in infected mice, but were similar between WT and $\mathrm{PAFR}^{-1-}$ mice. $\mathrm{PbA}$ infection up-regulated CCL2 (D) and CCL5 (E) in both infected mice. Results are expressed as mean \pm SEM and are representative of two independent experiments $(n=5)$. Significant differences are indicated by ${ }^{*} P<0.05,{ }^{* *} P<0.01$, and ${ }^{* * * *} P<0.001$ when compared to control counterparts or when compared to infected WT mice. 

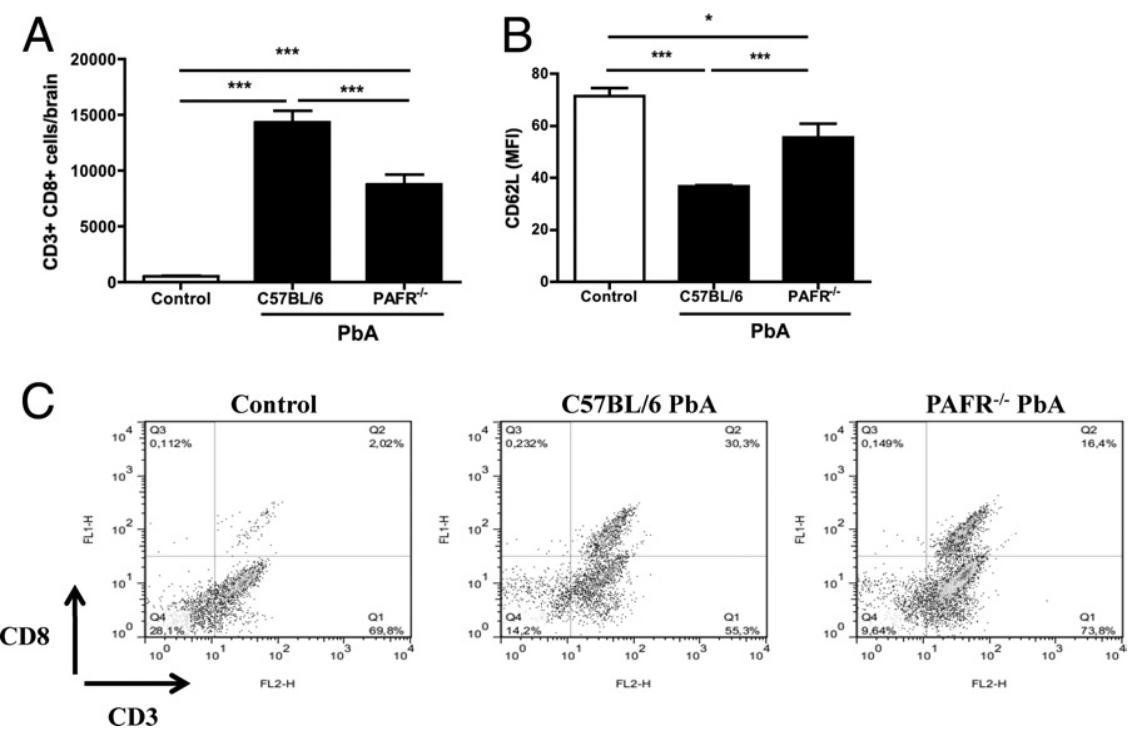

Figure 8. Reduced accumulation and activation of $\mathrm{CD}^{+}$lymphocytes in the brain of PbA-infected PAFR ${ }^{-1-}$ mice. Flow cytometry analyse of brain-sequestered leukocytes from uninfected control, PbA-infected WT mice with ECM, and infected CM-resistant $\mathrm{PAFR}^{-/-}$mice on day 7 after inoculation. Absolute numbers of $\mathrm{CD}^{+} \mathrm{T}$ cells. A: Numbers of $\mathrm{CD}^{+}{ }^{+} \mathrm{T}$ cells are shown in comparison to total number of leukocytes in the brain. B: Activated $\mathrm{CD}^{+}$lymphocytes expression of CD62L was also evaluated and expressed as MFI. C: Representative dot plots of $\mathrm{CD}^{+}$ $\mathrm{CD}^{+} \mathrm{T}$ cells. Results are expressed as mean \pm SEM and are representative of three independent experiments, with four pools of two to three mice per group. ${ }^{*} P<0.05$, ${ }^{*} * * * P<0.001$ when compared to uninfected control mice or infected WT mice. MFI, mean fluorescence intensity. was associated with $\mathrm{CD}^{+} \mathrm{T}$ cell activation, as determined by a decrease in CD62L expression. In contrast, $\mathrm{CD}^{+} \mathrm{T}$ cells were less activated in $\mathrm{PAFR}^{-1-}$ than WT mice (Figure 8B).

\section{Treatment With a PAFR Antagonist Partially Prevents CM}

To test the potential pharmacological use of PAFR blockade in the context of ECM, we used UK-74,505, a selective PAFR antagonist, in a therapeutic protocol-that is, treatment was initiated 3 days after infection. Treatment with the PAFR antagonist significantly delayed lethality in C57BL/6 infected mice (Figure 9C). Akin to results seen in $\mathrm{PAFR}^{-1-}$ mice, parasitemia (Figure 9A) and body weight variation (Figure 9B) were similar between treated animals and mice that received only the vehicle.

\section{Discussion}

In this study, we investigated the relevance of PAFR for the outcome of $\mathrm{PbA}$ infection using $\mathrm{PAFR}^{-1-}$ mice and a long-lasting and selective PAFR antagonist, UK74,505.
We demonstrated that PAFR deletion or antagonism significantly delayed death in a model of ECM induced by infection with $\mathrm{PbA}$. Parasitemia increased similarly in all groups, suggesting that PAFR is not relevant for parasite replication and that the compound does not appear to have any significant antimalarial properties. Therefore, PAFR appears to be relevant for the inflammatory events, which are eventually associated with premature death of the host. Some PAFR ${ }^{-1-}$ infected mice eventually die around day 7 after inoculation, maybe as a consequence of these inflammatory events. However, the immune response could be controlled in some knockout mice (60\%) that recovered their weight, and animals survived past day 7 after inoculation, although this explanation remains speculative. Indeed, in brain of $\mathrm{PAFR}^{-1-}$ infected mice, there was significant reduction in vascular plugging and hemorrhage, decreased levels of IL- $1 \beta$, decreased number and state of activation of $\mathrm{CD}^{+} \mathrm{T}$ cells, and markedly reduced changes in vascular permeability.

Mice that die of ECM develop a neurological condition characterized by paralysis, ataxia, seizures, and coma, resulting in high mortality. ${ }^{28} \mathrm{CD}^{+} \mathrm{T}$ cell sequestration and activation seem to be essential events for the pathogenesis of ECM in PbA-infected C57BL/6 mice, and
A

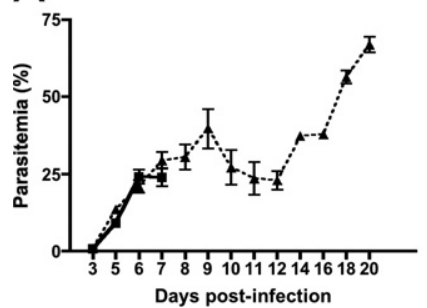

B

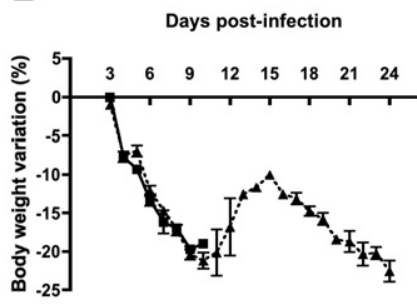

C

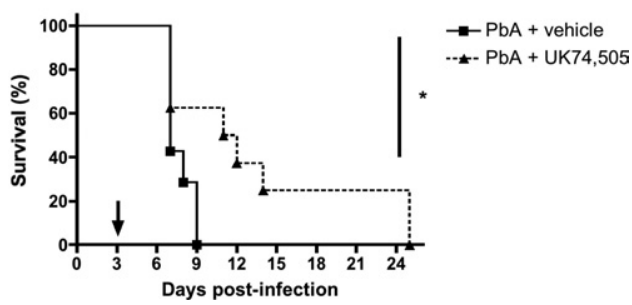

Figure 9. Treatment with a PAFR antagonist prevents partially against CM. UK-74,505 was provided orally, once a day, at a dose of $10 \mathrm{mg} / \mathrm{kg}$, from day 3 until death after infection in infected WT mice. Survival, parasitemia, and body weight variations were analyzed. Shown are time courses of parasitemia (A) and body weight variations (\%) (B), with no differences between the groups. Also shown is the percentage of survival in PbA-infected mice (C), where solid lines denote vehicle-treated mice $(n=8)$ and dashed lines, UK-74,505-treated mice $(n=8)$. Survival curves were significantly different, with ${ }^{*} P<0.05$. Each point of parasitemia and weight loss is expressed as mean \pm SEM. 
$\mathrm{CD}^{+}$T-cell depletion prevented neurological signs of ECM. ${ }^{4-7}$ Our data show a clear reduction of CD8 ${ }^{+}$T cells accumulation in the absence of a functional PAFR. The lymph node homing receptor CD62L (L-selectin) is highly expressed on naive $T$ cells and down-regulated after T-cell activation. ${ }^{29}$ The expression of CD62L in $\mathrm{CD}^{+} \mathrm{T}$ cells was significantly reduced in infected WT mice but to a lesser extent in infected $\mathrm{PAFR}^{-1-}$ mice. Therefore, activation of $\mathrm{CD}^{+} \mathrm{T}$ cells was reduced in the brain of $\mathrm{PAFR}^{-1-}$ mice, indicating that absence of PAFR is impairing $\mathrm{CD}^{+} \mathrm{T}$ cell activation and accumulation to the central nervous system.

Leukocyte rolling and adhesion in the pial vasculature was similar in $\mathrm{PAFR}^{-1-}$ and WT mice infected with PbA. Previous work from our group also showed that absence of PAFR attenuated experimental allergic encephalomyelitis, but the milder disease in $\mathrm{PAFR}^{-1-}$ was independent of rolling and adhesion of leukocytes in the pial microvasculature. ${ }^{17}$ ICAM-1 adhesion molecule has been linked to $\mathrm{CM}$ as a result of its role in $\mathrm{PRBC}$ and T-cell adhesion to brain endothelial cells. ${ }^{30}$ VCAM-1 may also play a role in the pathogenesis of $\mathrm{CM}^{31}$ In our model of ECM, expression of ICAM-1 and VCAM-1 was enhanced by infection but was not different in WT and $\mathrm{PAFR}^{-1-}$ mice. Similarly, there were only minor changes in expression of chemokines in brain of infected WT and $\mathrm{PAFR}^{-1-}$ mice, providing a molecular basis for the finding that overall rolling and adhesion were not different in WT and PAFR ${ }^{-1-}$ mice. In contrast to normal overall rolling and adhesion, there was decreased number of $\mathrm{CD}^{+} \mathrm{T}$ cells in the brain of infected $\mathrm{PAFR}^{-1-}$ mice, as discussed above. Therefore, although there is similar number of overall leukocyte/endothelial cell interactions in the brain, infiltration of specific leukocytes subsets is deficient in $\mathrm{PAFR}^{-1-}$ mice. This is consistent with findings that activated lymphocytes express PAFR on their surface ${ }^{32}$ and that lipid mediators may selectively modulate lymphocyte subset migration in a tissue-specific manner. ${ }^{33}$

Although the precise mechanisms by which $\mathrm{CD}^{+} \mathrm{T}$ cells mediate cerebral pathology are still unclear, it has been suggested that $\mathrm{CD}^{+} \mathrm{T}$ cells may damage the BBB via the induction of endothelial cells apoptosis in a perforin-dependent process. ${ }^{9-11}$ Apoptosis of endothelial cells may represent a critical event for the development of ECM in the mouse model. ${ }^{34}$ After caspase- 3 activation, Lackner et $\mathrm{al}^{23}$ found activation of apoptosis in brain endothelial cells in the early course of $\mathrm{PbA}$ infection, even when clinical signs were only mild. Interestingly, caspase-3 immunoreactive endothelial cells were primarily found in vessels with extensive leukocyte sequestration. ${ }^{23}$ In our study, we observed reduced expression of cleaved caspase-3 in PAFR ${ }^{-1-}$ mice, which was associated with decrease in the number of leukocytes and endothelial cells undergoing apoptosis. It is unclear why there was less apoptosis in the system and how PAFR activation would lead to enhanced endothelial cell and leukocyte apoptosis. However, it has been shown that activation of PAFR causes apoptosis of certain leukocytes $^{35}$ and is relevant for the capacity of oxidized lipoproteins to induce apoptosis of vascular endothelial cells. ${ }^{36}$ There was significant inhibition of plugging in the cerebral circulation of infected $\mathrm{PAFR}^{-1-}$ mice. Decreased plugging could account for the decrease in endothelial cell apoptosis observed, as leukocytes, platelets, and pRBC within the microvasculature may induce a pro-inflammatory cascade that ultimately promotes endothelial cell apoptosis. ${ }^{6,9,11}$ However, in contrast to human platelets, murine platelets are not responsive to PAF and do not express PAFR, ${ }^{37}$ but this receptor is expressed at high levels on murine leukocytes and endothelial cells. ${ }^{38}$ Regardless of the mechanisms explaining decreased apoptosis in $\mathrm{PAFR}^{-1-}$ mice, it is clear that decreased apoptosis of leukocytes and endothelial cells may contribute to the protected phenotype of $\mathrm{PAFR}^{-1-}$ mice.

PAF is a lipid mediator involved not only with the recruitment and activation of leukocytes, ${ }^{12}$ but it is also able to induce direct changes in BBB permeability in vitro. ${ }^{39}$ After infection by $\mathrm{PbA}, \mathrm{BBB}$ is compromised, and this has been considered one of the major events in the pathogenesis of ECM. ${ }^{40,41}$ In the present study, cerebral vascular permeability was increased after infection by $\mathrm{PbA}$, as quantified through EB leakage. More importantly, there was virtual absence of changes in vascular permeability in the brain of infected PAFR $^{-1-}$ mice. Thus, we hypothesized that $\mathrm{CD}^{+} \mathrm{T}$ cell-dependent caspase-3-mediated apoptosis of endothelial cells coupled with direct activation of PAFR may be responsible for BBB breakdown and hemorrhage in the brain of $\mathrm{PbA}$-infected mice.

In conclusion, these results constitute strong evidence that PAFR play an important role during ECM. More importantly, experiments with a long-lasting orally bioavailable PAFR antagonist ${ }^{14}$ showed that the protective effects of PAFR blockade was still present when the compound was provided after infection and before the major symptoms had appeared. To our knowledge, this is the first demonstration that PAFR signaling is critical for development of ECM. Moreover, our data support PAFR antagonism as an inhibitor of ECM. Equivalent studies in humans to understand the potential role of this pathway in disease are required.

\section{Acknowledgments}

We thank Carlos Henrique da Silva and Frankcinéia Assis for their technical assistance.

\section{References}

1. World Health Organization: Severe falciparum malaria: World Health Organization, communicable diseases cluster. Trans R Soc Trop Med Hyg 2000, 94:S1-S90

2. van der Heyde HC, Nolan J, Combes V, Gramaglia I, Grau GE: A unified hypothesis for the genesis of cerebral malaria: sequestration, inflammation and hemostasis leading to microcirculatory dysfunction. Trends Parasitol 2006, 22:503-508

3. Hearn J, Rayment N, Landon DN, Katz DR, de Souza JB: Immunopathology of cerebral malaria: morphological evidence of parasite sequestration in murine brain microvasculature. Infect Immun 2000, 68:5364-5376

4. Yañez DM, Manning DD, Cooley AJ, Weidanz WP, van der Heyde $\mathrm{HC}$ : Participation of lymphocyte subpopulations in the pathogen- 
esis of experimental murine cerebral malaria. J Immunol 1996 157:1620-1624

5. Potter S, Chaudhri G, Hansen A, Hunt NH: Fas and perforin contribute to the pathogenesis of murine cerebral malaria. Redox Rep 1999, 4:333-335

6. Belnoue E, Kayibanda M, Vigario AM, Deschemin JC, van Rooijen N, Viguier M, Snounou G, Rénia L: On the pathogenic role of brainsequestered alphabeta $\mathrm{CD}^{+} \mathrm{T}$ cells in experimental cerebral malaria. J Immunol 2002, 169:6369-6375

7. Rénia L, Potter SM, Mauduit M, Rosa DS, Kayibanda M, Deschemin JC, Snounou G, Gruner AC: Pathogenic T cells in cerebral malaria. Int J Parasitol 2006, 36:547-554

8. Baptista FG, Pamplona A, Pena AC, Mota MM, Pied S, Vigário AM: Accumulation of Plasmodium berghei-infected red blood cells in the brain is crucial for the development of cerebral malaria in mice. Infect Immun 2010, 78:4033-4039

9. Potter S, Chan-Ling T, Ball HJ, Mansour H, Mitchell A, Maluish L, Hunt $\mathrm{NH}$ : Perforin mediated apoptosis of cerebral microvascular endothelial cells during experimental cerebral malaria. Int J Parasitol 2006, $36: 485-496$

10. Wassmer SC, Combes V, Candal FJ, Juhan-Vague I, Grau GE: Platelets potentiate brain endothelial alterations induced by Plasmodium falciparum. Infect Immun 2006, 74:645-653

11. Suidan GL, McDole JR, Chen Y, Pirko I, Johnson AJ: Induction of blood brain barrier tight junction protein alterations by CD8 T cells. PLOS ONE 2008, 3:e3037

12. Chao W, Olson MS: Platelet-activating factor: receptors and signal transduction. Biochem J 1993, 292:617-629

13. Ishii S, Shimizu T: Platelet-activating factor (PAF) receptor and genetically engineered PAF receptor mutant mice. Prog Lipid Res 2000 39:41-82

14. Alabaster VA, Keir RF, Parry MJ, de Souza RN: UK-74,505, a novel and selective PAF antagonist, exhibits potent and long lasting activity in vivo. Agents Actions Suppl 1991, 34:221-227

15. Grau GE, Piguet PF, Engers HD, Louis JA, Vassali P, Lambert PH: $\mathrm{L} \mathrm{T} 4^{+} \mathrm{T}$ lymphocytes play a major role in the pathogenesis of murine cerebral malaria. J Immunol 1986, 137:2348-2354

16. Fauconnier M, Bourigault ML, Meme S, Szeremeta F, Palomo J, Danneels A, Charron S, Fick L, Jacobs M, Beloeil JC, Ryffel B, Quesniaux VF: Protein kinase C-theta is required for development of experimental cerebral malaria. Am J Pathol 2011, 178:212-221

17. Rodrigues DH, Lacerda-Queiroz N, de Miranda AS, Fagundes CT, Campos RD, Arantes RE, Vilela MD, Rachid MA, Teixeira MM, Teixeira AL: Absence of PAF receptor alters cellular infiltrate but not rolling and adhesion of leukocytes in experimental autoimmune encephalomyelitis. Brain Res 2011, 1385:298-306

18. Sousa LP, Carmo AF, Rezende BM, Lopes F, Silva DM, Alessandri AL, Bonjardim CA, Rossi AG, Teixeira MM, Pinho V: Cyclic AMP enhances resolution of allergic pleurisy by promoting inflammatory cell apoptosis via inhibition of PI3K/Akt and NF-kappaB. Biochem Pharmacol 2009, 78:396-405

19. Belayev L, Busto R, Zhao W, Ginsberg MD: Quantitative evaluation of blood-brain barrier permeability following middle cerebral artery occlusion in rats. Brain Res 1996, 739:88-96

20. Deb C, Howe CL: Functional characterization of mouse spinal cord infiltrating $\mathrm{CD}^{+}$lymphocytes. J Neuroimmunol 2009, 214:33-42

21. Souza DG, Fagundes CT, Sousa LP, Amaral FA, Souza RS, Souza AL, Kroon EG, Sachs D, Cunha FQ, Bukin E, Atrasheuskaya A, Ignatyev $G$, Teixeira MM: Essential role of platelet-activating factor receptor in the pathogenesis of dengue virus infection. Proc Natl Acad Sci USA 2009, 106:14138-14143

22. Favre N, Da Laperousaz C, Ryffel B, Weiss NA, Imhof BA, Rudin W, Lucas R, Piguet PF: Role of ICAM-1 (CD54) in the development of murine cerebral malaria. Microbes Infect 1999, 1:961-968
23. Lackner P, Burger C, Pfaller K, Heussler V, Helbok R, Morandell M, Broessner G, Tannich E, Schmutzhard E, Beer R: Apoptosis in experimental cerebral malaria: spatial profile of cleaved caspase-3 and ultrastructural alterations in different disease stages. Neuropathol Appl Neurobiol 2007, 33:560-571

24. Stafforini DM, Mclntyre TM, Zimmerman GA, Prescott SM: Plateletactivating factor, a pleiotrophic mediator of physiological and pathological processes. Crit Rev Clin Lab Sci 2003, 40:643-672

25. Miu J, Mitchell AJ, Müller M, Carter SL, Manders PM, McQuillan JA, Saunders BM, Ball HJ, Lu B, Campbell IL, Hunt NH: Chemokine gene expression during fatal murine cerebral malaria and protection due to CXCR3 deficiency. J Immunol 2008, 180:1217-1230

26. Campanella GS, Tager AM, El Khoury JK, Thomas SY, Abrazinski TA, Manice LA, Colvin RA, Luster AD: Chemokine receptor CXCR3 and its ligands CXCL9 and CXCL10 are required for the development of murine cerebral malaria. Proc Natl Acad Sci USA 2008, 105:48144819

27. Allan SM, Tyrrell PJ, Rothwell NJ: Interleukin-1 and neuronal injury. Nat Rev Immunol 2005, 5:629-640

28. Hunt NH, Golenser J, Chan-Ling T, Parekh S, Rae C, Potter S, Medana IM, Miu J, Ball HJ: Immunopathogenesis of cerebral malaria. Int J Parasitol 2006, 36:569-582

29. Butcher EC, Picker LJ: Lymphocyte homing and homeostasis. Science 1996, 272:60-66

30. Tripathi AK, Sullivan DJ, Stins MF: Plasmodium falciparum-infected erythrocytes increase intercellular adhesion molecule 1 expression on brain endothelium through NF-kappaB. Infect Immun 2006, 74: 3262-3270

31. Herbas MS, Okazaki M, Terao E, Xuan X, Arai H, Suzuki H: alphaTocopherol transfer protein inhibition is effective in the prevention of cerebral malaria in mice. Am J Clin Nutr 2010, 91:200-207

32. Calabresse C, Nguer MC, Pellegrini O, Benveniste J, Richard Y, Thomas Y: Induction of high-affinity paf receptor expression during $T$ cell activation. Eur J Immunol 1992, 22:1349-1355

33. Landgraf RG, Nossi DF, Sirois P, Jancar S: Prostaglandins, leukotrienes and PAF selectively modulate lymphocyte subset and eosinophil infiltration into the airways in a murine model of asthma. Prostaglandins Leukot Essent Fatty Acids 2007, 77:163-172

34. Bienvenu AL, Gonzalez-Rey E, Picot S: Apoptosis induced by parasitic diseases. Parasit Vectors 2010, 3:106

35. el Azzouzi B, Jurgens P, Benveniste J, Thomas Y: Immunoregulatory functions of paf-acether. IX. Modulation of apoptosis in an immature T cell line. Biochem Biophys Res Commun 1993, 190:320-324

36. Chen $\mathrm{CH}$, Jiang T, Yang JH, Jiang W, Lu J, Marathe GK, Pownall HJ, Ballantyne CM, McIntyre TM, Henry PD, Yang CY: Low-density lipoprotein in hypercholesterolemic human plasma induces vascular endothelial cell apoptosis by inhibiting fibroblast growth factor 2 transcription. Circulation 2003, 107:2102-2108

37. Terashita Z, Imura Y, Nishikawa K: Inhibition by CV-3988 of the binding of $[3 \mathrm{H}]$-platelet activating factor (PAF) to the platelet. Biochem Pharmacol 1985, 34:1491-1495

38. Prescott SM, Zimmerman GA, Stafforini DM, Mclntyre TM: Plateletactivating factor and related lipid mediators. Annu Rev Biochem 2000, 69:419-445

39. Fang W, Geng X, Deng Y, Li Y, Shang E, Cen J, Lv P: Platelet activating factor induces blood brain barrier permeability alteration in vitro. J Neuroimmunol 2011, 230:42-47

40. Pino P, Taoufiq Z, Nitcheu J, Vouldoukis I, Mazier D: Blood-brain barrier breakdown during cerebral malaria: suicide or murder? Thromb Haemost 2005, 94:336-340

41. Combes V, Coltel N, Faille D, Wassmer SC, Grau GE: Cerebral malaria: role of microparticles and platelets in alterations of the blood-brain barrier. Int J Parasitol 2006, 36:541-546 